\title{
Sistem Penunjang Keputusan Penerima Kartu Indonesia Pintar Menggunakan Metode Simple Additive Weighting (SAW)
}

\author{
Andi Saryoko ${ }^{1}$, Sholihin Muttaqin², Rahmat Hidayat ${ }^{3}$ \\ ${ }^{1}$ STMIK Nusa Mandiri Jakarta \\ e-mail: andi.asy@nusamandiri.ac.id \\ ${ }^{2}$ STMIK Nusa Mandiri Jakarta \\ e-mail: solihinmuttaqin@gmail.com \\ ${ }^{3}$ Universitas Bina Sarana Informatika \\ e-mail: rahmat.rhh@bsi.ac.id
}

\begin{abstract}
Education is very important given the Government programs which require a minimum of 9 years of education, but many societies among medium size down unable to finance the education of their sons and daughters to 9 years. Indonesia Smart program is one of a national program that aims to increase the number of elementary and secondary education participation, increase sustainability education marked with menurunya numbers dropouts, as well as improving secondary education students readiness to enter the job market or proceed to higher education.In this research will be made a decision support system (SPK) to facilitate in the selection criteria for the Smart Card recipient Indonesia students who deserve help, the method used in this research is the Simple Additive Weighting (SAW), this method was chosen because it can determine the value weights for each attribute, and then do the perangkingan process will determine the alternatives to get more accurate results are eligible to receive smart cards help indonesia. By applying the method of Simple Additive Weighting $(S A W)$ hope to provide ease in taking decisions which are appropriate and accurate.
\end{abstract}

Key Word: decision support system, the Smart Card recipient Indonesia, Simple Additive Weighting

\section{PENDAHULUAN}

Program Indonesia Pintar melalui KIP adalah pemberian bantuan tunai pendidikan kepada seluruh anak usia sekolah (6-21 tahun) yang menerima KIP, atau yang berasal dari keluarga miskin dan rentan, atau anak yang memenuhi kriteria yang telah ditetapkan sebelumnya. Program Indonesia Pintar melalui KIP merupakan bagian penyempurnaan dari Program Bantuan Siswa Miskin (BSM) sejak akhir 2014.

Pendidikan sangat penting mengingat Program Pemerintah yang mewajibkan pendidikan minimal 9 tahun, namun banyak masyarakat kalangan menegah kebawah yang tidak mampu membiayai pendidikan putra-putri mereka sampai 9 tahun.Program Indonesia Pintar adalah salah satu program nasional yang bertujuan untuk meningkatkan angka partisipasi pendidikan dasar dan menengah, meningkatkan keberlanjutan pendidikan yang ditandai dengan menurunya angka putus sekolah, serta meningkatkan kesiapan siswa pendidikan menengah untuk memasuki pasar kerja atau melanjutkan ke jenjang pendidikan tinggi. Dalam penelitian ini akan dibuat sebuah sistem penunjang keputusan (SPK) untuk memudahkan dalam pemilihan kriteria penerima Kartu Indonesia Pintar siswa yang layak mendapat bantuan, metode yang yang digunakan dalam penelitian ini adalah Simple Additive Weighting (SAW), metode ini dipilih karena dapat menentukan nilai bobot untuk setiap atribut, kemudian dilakukan proses perangkingan yang akan menentukan alternatif untuk mendapatkan hasil yang lebih akurat yang berhak menerima bantuan kartu indonesia pintar. Dengan menerapkan metode Simple Additive Weighting (SAW) berharap dapat memberikan kemudahan dalam mengambil keputusan yang tepat dan akurat.

Menurut (Eniyati,2011:171) Pada penelitian ini akan diangkat suatu kasus yaitu mencari alternative terbaik bedasarkan kriteria-kriteria yang telah ditentukan dengan menggunakan metode SAW (Simple Additive Weighting) Penelitian dilakukan dengan mencari nilai bobot untuk setiap atribut, kemudian dilakukan proses perangkingan yang akan menentukan alternatif yang optimal, yaitu siswa terbaik.

Berdasarkan hal tersebut, maka diperlukan sebuah sistem aplikasi untuk memudahkan menentukan penerima kartu Indonesia pintar terutama di SD Jatimakmur IV Bekasi dengan menerapkan Metode Simple Additive Weigthing (SAW).

Tujuan yang akan dicapai dalam penelitian ini yaitu memudahkan dan membantu petugas dalam 
melakukan pendataan siswa yang menjadi penerima bantuan, membantu dalam menentukan penerima KIP menggunakan metode Metode Simple Additive Weinghting (SAW) dan mengetahui tingkat peringkatan.

Dalam penelitian ini dimulai dari mengambil sempel data tanggungan orang tua, penghasilan orang tua, pekerjaan orang tua, kelas dan status keadaan orang tua siswa di SDN Jatimakmur IV Kota Bekasi. Setelah mendapatkan data yang telah di berikan oleh pihak operator sekolah dihitung menggunakan metode SAW.

Metode SAW sering juga dikenal istilah metode penjumlahan terbobot. Konsep dasar metode SAW adalah mencari penjumlahan terbobot dari rating kinerja pada setiap alternatif dari semua aribut. Metode SAW membutuhkan proses normalisasi matriks keputusan (X) ke suatu skala yang dapat diperbandingkan dengan semua rating alternatif yang ada. Formula untuk melakukan normalisasi tersebut adalah sebagai berikut :

$\mathrm{r}_{\mathrm{ij}}= \begin{cases}\frac{\mathrm{x}_{\mathrm{ij}}}{\operatorname{Max}_{\mathrm{i}}} & \text { jika jadalah atribut keuntungan (benefit) } \\ \frac{\operatorname{Min}_{\mathrm{i}}}{\mathrm{x}_{\mathrm{ij}}} & \text { jika jadalah atribut biaya (cost) }\end{cases}$

Gambar II.1.

Formula Untuk Normalisasi

Dimana rij adalah rating kinerja ternormalisasi dari alternatif $\mathrm{Ai}$ pada atribut $\mathrm{Cj} ; \mathrm{i}=1,2, \ldots . \mathrm{m}$ dan $\mathrm{j}=1,2, \ldots$, n. Nilai preferensi untuk setiap alternatif (Vi) diberikan rumus sebagai berikut :

$$
\mathrm{V}_{\mathrm{i}}=\sum_{\mathrm{j}=1}^{\mathrm{n}} \mathrm{w}_{\mathrm{j}} \mathrm{r}_{\mathrm{ij}}
$$

Gambar II.2.

Nilai Prefensi Setiap Alternatif

Nilai Vi yang lebih besar mengindikasikan bahwa alternatif Ai lebih terpilih.

Penelitian Terkait yang sudah pernah dilakukan oleh beberapa peneliti yang lainnya adalah:

Menurut Riyanto, dkk (2015:1) sistem yang nantinya dibuat akan membantu petugas staf Pemuktahiran Data sebagai pendukung untuk penentuan penerima kartu KIP. Metode yang digunakan dalam penetuan penerima adalah Simple Additive Weighting (SAW), dimana mempunyai keunggulan dalam pengambilan keputusan yang lain terletak pada kemampuanya untuk melakukan penilaian secara lebih tepat karena berdasarkan pada nilai kriteria dan bobot prefesi yang sudah ditentukan.

Menurut Supriyanti (2013:67) Metode yang dipilih untuk menyelesaikan permasalahan dengan banyak kriteria adalah Simple Additive Weighting (SAW), salah satu metode yang dapat digunakan untuk memecahkan masalah Fuzzy MADM. Metode ini dipilih karena dapat menentukan bobot untuk setiap atribut, diikuti peringkat altenatif yang akan memilih penerima beasiswa berdasarkan boboy yang telah dibuat untuk mendapatkan hasil yang lebih akurat yang akan menerima beasiswa.

\section{METODOLOGI PENELITIAN}

Adapun langkah-langkah penyusunan yang dilakukan ditunjukan pada gambar berikut:

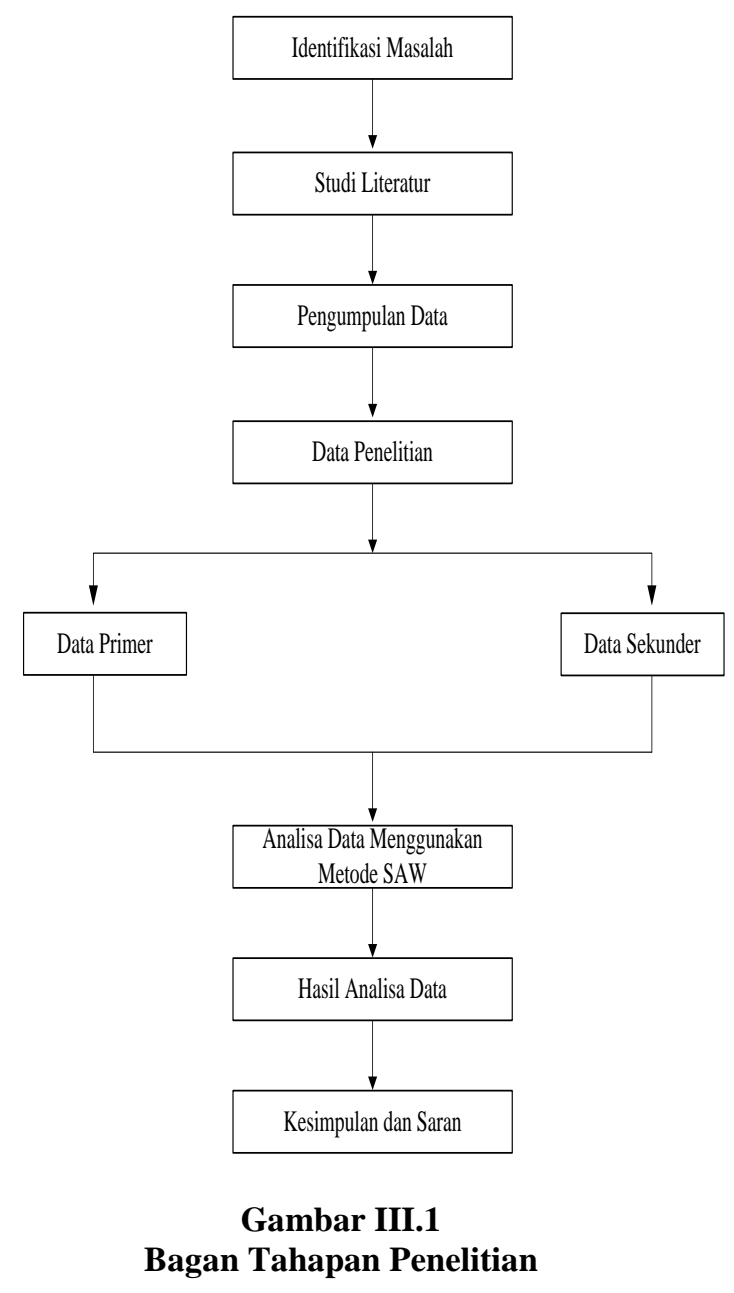

Tahapan metodologi penelitian dijelaskan secara umum sebagai berikut:

1. Identifikasi Masalah

Melakukan identifikasi pada suatu masalah merupakan tahap awal pada proses penelitian. Tahapan ini dibangun berdasarkan rumusan 
masalah yang didasari atas latar belakang masalah.

2. Studi Literatur

Dilakukan dengan mempelajari dan memahami teori-teori yang digunakan, yaitu diantaranya mencari faktor-faktor yang menjadi syarat Sistem Pendukung Keputusan, Metode Simple Additive Weighting (SAW) dan metode pengumpulan data, data-data tersebut dicari dengan cara mengumpulkan literatur, jurnal nasional, browsing internet dan bacaan-bacaan yang ada kaitannya dengan topik baik berupa textbook atau paper.

3. Pengumpulan Data

Tahapan ini merupakan cara mengumpulkan data yang dilakukan dengan 2 cara, yaitu observasi dan wawancara kepada pihak Operator Sekolah SD Negeri Jatimakmur IV Kota Bekasi terkait parameter menentukan penerima Program Kartu Indonesia Pintar di SDN Jatimakmur IV.

4. Data Penelitian

Dalam penelitian ini data yang dibutuhkan dibagi menjadi dua yaitu data primer dan data skunder.

5. Analisa Data Menggunakan Metode Simple Additive Weighting (SAW)

Analisa data dalam penelitian ini menggunakan metode Simple Additive Weighting, yang dilakukan secara kuantitatif yaitu metode penelitian yang bersifat deskriptif dan lebih banyak menggunakan analisis. Penelitian ini dilakukan dengan mengumpulkan data hasil analisis untuk mendapatkan informasi yang harus disimpulkan.

6. Hasil Analisa Data

Setelah tahap analisis data dengan menggunakan metode Simple Additive Weghting (SAW) dihasilkan suatu hasil analisis yang merupakan hasil dari suatu proses penelitian yang dilakukan.

7. Kesimpulan dan Saran

Kesimpulan merupakan tahap akhir dari uraian proses penelitian dengan menyimpulkan permasalahan yang ada.

Instrumen penelitian merupakan alat yang digunakan untuk melakukan sesuatu. Sedangkan penelitian memiliki arti pemeriksaan, penyelidikan, kegiatan pengumpulan, pengolahan, analisis dan penyajian data secara sistematis dan objektif.

Dari pengertian diatas maka instrumen penelitian dapat disimpulkan alat atau fasilitas yang digunakan oleh peneliti dalam mengumpulkan data penelitian agar pekerjaannya menjadi lebih mudah dan baik dalam arti lebih cermat, lengkap, sistematis sehingga lebih mudah diolah. Instrumen yang digunakan dalam penelitian ini adalah pedoman wawancara, pedoman observasi dan pedoman studi pustaka.

\section{Pedoman Observasi}

Observasi yang digunakan dalam penelitan ini adalah observasi sistematis, yaitu observasi yang dilakukan oleh pengamat dengan menggunakan pedoman sebagai instrumen pengamatan. Pedoman observasi berisi sebuah daftar siswa calon penerima Kartu Indonesia Pintar yang akan diamati.

2. Pedoman Studi Pustaka

Dalam menggunakan pedoman ini peneliti membuat daftar variabel yang akan digunakan pada penelitian ini yang terdapat pada jurnal. Apabila terdapat variabel yang dicari, peneliti tinggal menambahkan jika diperlukan.

3. Pedoman Wawancara

Dalam penelian ini, wawancara dilakukan untuk memperoleh informasi lebih mendalam dari partisipan. Dalam melakukan wawancara penulis akan mengetahui hal-hal yang lebih mendalam mengenai partisipan dalam menginterpretasikan situasi yang terjadi, dimana hal ini tidak bisa dilakukan melalui observasi.

Jadi dari instrumen penelitian pedoman observasi, pedoman studi pustaka dan pedoman wawancara peneliti mendapatkan 5 variabel.

Tabel III.1

Tabel Variabel Penelitian

\begin{tabular}{cl}
\hline Kriteria & \multicolumn{1}{c}{ Nama Kriteria } \\
\hline $\mathrm{C}_{1}$ & $\begin{array}{l}\text { Jumlah Tanggungan } \\
\text { Orang Tua }\end{array}$ \\
\hline $\mathrm{C}_{2}$ & $\begin{array}{l}\text { Jumlah Penghasilan } \\
\text { Orang Tua }\end{array}$ \\
\hline $\mathrm{C}_{3}$ & Pekerjaan Orang Tua \\
\hline $\mathrm{C}_{4}$ & Kelas \\
\hline $\mathrm{C}_{5}$ & Keadaan Orang Tua \\
\hline
\end{tabular}

Metode pengumpulan data merupakan faktor penting demi keberhasilan penelitian. Hal ini berkaitan dengan bagaimana cara mengumpulkan data, siapa sumbernya, dan alat apa saja yang digunakan. Dalam pembuatan skripsi ini metode pengumpulan data yang digunakan adalah:

a. Data Primer

Data Primer adalah data yang dikumpulkan langsung oleh penulis dari responden, dan bukan berasal dari pengumpulan data yang pernah dilakukan sebelumnya. Data primer juga diartikan sebagai data yang diperoleh dari sumber-sumber asli. Sumber asli disini diartikan sebagai sumber pertama dimana darimana data tersebut diperoleh. Dalam pengumpulan data primer dalam penelitian ini menggunakan metode observasi dan wawancara.

b. Data Skunder

Sedangkan dalam pengumpulan data skunder menggunakan buku, jurnal, publikasi dan lain- 
lain. Penulis mengumpulkan data dan informasi melalui studi pustaka yang bersifat sekunder yaitu data-data yang diperoleh melalui bukubuku referensi, dokumentasi, literatur, jurnal dan informasi lainnya yang ada hubungannya dengan masalah yang diteliti.

Populasi adalah wilayah generalisasi yang terdiri atas obyek atau subyek yang mempunyai kualitas dan karakteristik tertentu yang ditetapkan oleh peneliti untuk dipelajari kemudian ditarik kesimpulannya (Sugiyono, 2009:80).

Populasi dari penelitian ini adalah data siswa calon penerima program Kartu Indonesia Pintar yang terdaftar di SD Negeri Jatimakmur IV dengan jumlah 50 siswa tahun ajaran 2016.

Sampel dalam penelitian ini adalah data siswa calon penerima program Kartu Indonesia Pintar di SD Negeri Jatimakmur IV. Hal ini dilakukan karena mengingat jumlah populasi $<=100$, maka penulis mengambil sampel dari jumlah populasi yang ada yaitu 50 siswa. Berikut adalah data sampel siswa calon penerima program Kartu Indonesia Pintar di SD Negeri Jatimakmur IV periode tahun 2016:

Metode $S A W$ merupakan metode yang paling sederhana dan paling banyak digunakan. Metode ini juga metode yang paling mudah untuk diaplikasikan. Metode $S A W$ sering juga dikenal metode penjumlahan terbobot.

Microsoft Excel atau sering disebut dengan Excel merupakan program untuk mengolah angka/data secara otomatis, yang meliputi perhitungan dasar matematika, penggunaan fungsifungsi tertentu, pengolahan data, pembuatan grafik dan manajemen data. Selain itu Microsoft Excel juga dapat digunakan untuk berbagai urusan, dimulai dari yang sederhana, hingga urusan yang kompleks.

\section{HASIL DAN PEMBAHASAN}

Data dalam penelitian ini menentukan penerima Kartu Indonesia Pintar bersumber dari SDN Jatimakmur IV dan sifatnya rahasia, dengan jumlah total data pada penelitian ini adalah sebanyak 50 siswa. Setiap siswa disebut sebagai suatu altrnatif ( $\mathrm{A}_{1}, \mathrm{~A}_{2}, \mathrm{~A}_{3}$ dan seterusnya).

Variabel input yang digunakan untuk penelitian ini adalah sebagai berikut:

1. Jumlah Tanggungan Orang Tua

2. Jumlah Penghasilan Orang Tua

3. Pekerjaan Orang Tua

4. Kelas

5. Keadaan Orang Tua

Ada beberapa langkah untuk melakukan perhitungan untuk menentukan penerima Kartu Indonesia Pintar menggunakan Simple Additive Weghting (SAW):

1. Data Alternatif Data Siswa Calon Penerima Kartu Indonesia Pintar

2. Kriteria dan Bobot

Langkah kedua menentukan kriteria yang akan dijadikan acuan dalam pengambilan keputusan, yaitu $\mathrm{C} 1$.

a. Jumlah Tanggungan Orang Tua

Variabel Jumlah Tanggungan Orang Tua terbagi atas 4 bilangan fuzzy yaitu:

Kurang Penting (KP) : 1

Cukup Penting (CP)

Penting (P)

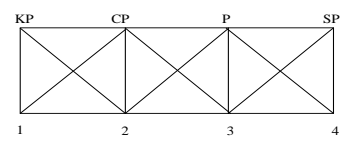

Sangat Penting (SP) : : 4

Nilai dan bobot untuk Variabel Jumlah Tanggungan Orang Tua ditunjukan pada Tabel IV.2.

Tabel IV.2

Jumlah Tanggungan Orang Tua

\begin{tabular}{ccc}
\hline $\begin{array}{c}\text { Jumlah } \\
\text { Tanggungan } \\
\text { Orang Tua }\end{array}$ & $\begin{array}{c}\text { Bilangan } \\
\text { Fuzzy }\end{array}$ & Bobot \\
\hline 1 Anak & Kurang Penting & 1 \\
\hline 2 Anak & Cukup Penting & 2 \\
\hline 3 Anak & Penting & 3 \\
\hline$\geq 4$ Anak & Sangat Penting & 4 \\
\hline
\end{tabular}

b. Jumlah Penghasilan Orang Tua

Variabel Jumlah penghasilan Orang Tua terbagi atas 4 bilangan

fuzzy yaitu: C2

Sangat Penting (SP): 4

Penting (P)

$: 3$

Cukup Penting (CP): 2

Kurang Penting (KP): 1

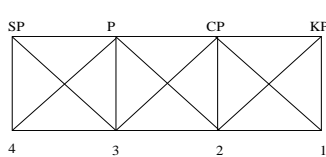

Nilai dan bobot untuk Variabel Penghasilan Orang Tua ditunjukan pada Tabel IV.3.

Tabel IV.3

Jumlah Penghasilan Orang Tua

\begin{tabular}{ccc}
\hline $\begin{array}{c}\text { Jumlah Penghasilan } \\
\text { Orang Tua }\end{array}$ & Bilangan Fuzzy & Bobot \\
\hline$\leq 500.000$ & Sangat Penting & 4 \\
\hline $500.000-1.000 .000$ & Penting & 3 \\
\hline $1.000 .000-2.000 .000$ & Cukup Penting & 2 \\
\hline$\geq 2.000 .000$ & Kurang Penting & 1 \\
\hline
\end{tabular}

c. Pekerjaan Orang Tua

Variabel Pekerjaan Orang Tua terbagi atas 5 bilangan fuzzy yaitu:

Tidak Penting (KP) : 1 
Kurang Penting (KP): 2

Cukup Penting (CP): 3

Penting $(\mathrm{P})$

Sangat Penting (SP): 5

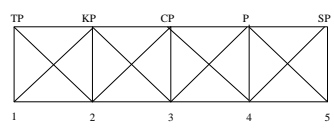

Nilai dan bobot untuk Variabel Pekerjaan

Orang Tua ditunjukan pada Tabel IV.4.

Tabel IV.4

Pekerjaan Orang Tua

\begin{tabular}{ccc}
\hline Pekerjaan & Bilangan Fuzzy & Bobot \\
\hline PNS/TNI/POLRI & Tidak Penting & 1 \\
\hline Karyawan Swasta & Kurang Penting & 2 \\
\hline Wiraswasta & Cukup Penting & 3 \\
\hline Buruh & Penting & 4 \\
\hline Tidak Bekerja & Sangat Penting & 5 \\
\hline
\end{tabular}

d. Kelas

Variabel Kelas terbagi atas 3 bilangan fuzzy yaitu:

Sangat Penting (SP): 4

Penting $(\mathrm{P}) \quad: 3$

Cukup Penting (CP): 2

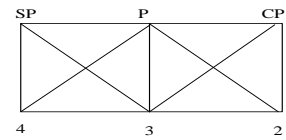

Nilai dan bobot untuk Variabel Kelas ditunjukan pada Tabel IV.5.

Tabel IV.5

Kelas

\begin{tabular}{cc}
\hline Bobot $(\mathbf{W})$ & Keterangan \\
\hline 0,5 & Tidak Penting \\
\hline 0,25 & Kurang Penting \\
\hline 0,50 & Cukup Penting \\
\hline 0,75 & Penting \\
\hline 1 & Sangat Penting \\
\hline
\end{tabular}

Keadaan Orang Tua

Variabel Keadaan Orang Tua terbagi atas 4 bilangan fuzzy yaitu:

Sangat Penting (SP): 4

Penting $(\mathrm{P})$

$: 3$

Cukup Penting (CP): 2

Kurang Penting (KP):

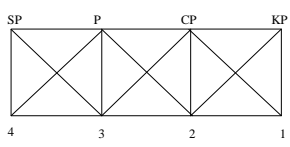

1

Nilai dan bobot untuk Variabel Keadaan

Orang Tua ditunjukan pada Tabel IV.6.
Tabel IV.6

Keadaan Orang Tua

\begin{tabular}{ccc}
\hline $\begin{array}{c}\text { Keadaan Orang } \\
\text { Tua }\end{array}$ & Bilangan Fuzzy & Bobot \\
\hline $\begin{array}{c}\text { Tidak Memiliki } \\
\text { Orang Tua }\end{array}$ & Sangat Penting (SP) & 4 \\
\hline Ayah Meninggal & Penting (P) & 3 \\
\hline Ibu Meninggal & Cukup Penting (CP) & 2 \\
\hline $\begin{array}{c}\text { Masih Memiliki } \\
\text { Orang Tua }\end{array}$ & Kurang Penting (KP) & 1 \\
\hline
\end{tabular}

3. Bobot Preferensi (W)

Langkah ketiga menentukan bobot preferensi atau tingkat kepentingan (W) setiap kriteria. Bobot kriteria yang digunakan dalam menentukan penerima Kartu Indonesia Pintar adalah sebagai berikut:

Tabel IV.7

Bobot Kepentingan Kriteria

\begin{tabular}{lcc}
\hline \multicolumn{1}{c}{ Kriteria (C) } & Bobot $(\mathbf{W})$ & Keterangan \\
\hline $\begin{array}{l}\mathrm{C} 1=\text { Jumlah tanggungan } \\
\text { Orang Tua }\end{array}$ & 0,50 & Cukup Penting \\
\hline $\begin{array}{l}\mathrm{C}_{2}=\text { Jumlah Penghasilan } \\
\text { Orang Tua }\end{array}$ & 0,75 & Penting \\
\hline $\mathrm{C}_{3}=$ Pekerjaan Orang & 0,50 & Cukup Penting \\
Tua & 0,25 & Cukup \\
\hline $\mathrm{C}_{4}=$ Kelas & 1 & Sangat Penting \\
\hline $\mathrm{C}_{5}=$ Keadaan Orang Tua & & \\
\hline
\end{tabular}

4. Nilai Rating Kecocokan Setiap Alternatif Pada Setiap Kriteria

Langkah keempat menentukan rating kecocokan setiap alternatif pada setiap kriteria yang telah ditentukan diatas

5. Matriks Keputusan

Setelah nilai rating alternatif pada setiap kriteria di tentukan langkah kelima adalah membuat matriks kaputusan (X) yang dibentuk dari tabel rating kecocokan dari setiap alternatif pada setiap kriteria. Nilai (X) setiap alternatif (A1) pada setiap kriteria $(\mathrm{C} 1)$ yang telah ditentukan.

6. Normalisasi Matriks Keputusan (X)

Langkah keenam melakukan proses normalisasi matriks keputusan $(\mathrm{X})$ kesuatu skala yang dapat diperbandingkan dengan semua rating alternatif yang ada.

$$
\boldsymbol{R}_{i j}=\frac{x_{i j}}{\operatorname{Max} x_{i j}}
$$


7. Matriks Ternormalisasi (R)

Hasil dari normalisasi matriks (Rij) membentuk matriks ternormalisasi (R).

8. Nilai Preferensi (V1)

Langkah kedelapan menghitung hasil akhir nilai preferensi (V1) diperoleh dari penjumlahan dari perkalian elemen baris matriks ternormalisasi (R) dengan bobot preferensi (W) yang bersesuaian dengan elemen kolom matriks (R).

\section{n

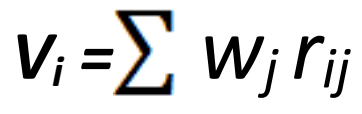 \\ $j=1$}

Bobot Preferensi : $0,50 \quad 0,75 \quad 0,50 \quad 0,25 \quad 1$

Dibawah ini adalah tabel hasil pengujian dimana nilai awal dari setiap alternatif diproses menggunakan metode Simple Additive Weghting (SAW) dan mendapatkan nilai hasil akhir dalam perhitungan seperti di atas, berikut tabel IV.10 dibawah ini.

Tabel IV.10

Hasil Pengujian

\begin{tabular}{|c|c|c|c|c|c|c|c|}
\hline & & $\mathrm{C} 1$ & $\mathrm{C} 2$ & C3 & $\mathrm{C} 4$ & C5 & \\
\hline No & $\begin{array}{c}\text { Alter } \\
\text { natif }\end{array}$ & $\begin{array}{c}\text { Jumlah } \\
\text { Tanggu } \\
\text { ngan } \\
\text { Orang } \\
\text { Tua }\end{array}$ & $\begin{array}{c}\text { Juml } \\
\text { ah } \\
\text { Peng } \\
\text { hasil } \\
\text { an } \\
\text { Oran } \\
\text { g } \\
\text { Tua }\end{array}$ & $\begin{array}{c}\text { Pekerja } \\
\text { an } \\
\text { Orang } \\
\text { Tua }\end{array}$ & $\begin{array}{c}\text { Kela } \\
\mathrm{s}\end{array}$ & $\begin{array}{c}\text { Kead } \\
\text { aan } \\
\text { Oran } \\
\text { g } \\
\text { Tua }\end{array}$ & $\begin{array}{c}\text { Juml } \\
\text { ah } \\
\text { Akhi } \\
\text { r }\end{array}$ \\
\hline 1 & $\mathrm{~A}_{1}$ & 0,8 & 1 & 1 & 1 & 1 & 2,90 \\
\hline 2 & $\mathrm{~A}_{2}$ & 0,2 & 0,75 & 0,8 & 1 & 0,25 & 1,56 \\
\hline 3 & $\mathrm{~A}_{3}$ & 0,2 & 0,5 & 0,4 & 1 & 0,25 & 1,18 \\
\hline 4 & $\mathrm{~A}_{4}$ & 0,8 & 0,75 & 0,6 & 1 & 0,25 & 1,76 \\
\hline 5 & $\mathrm{~A}_{5}$ & 0,2 & 1 & 0,8 & 1 & 0,25 & 1,75 \\
\hline 6 & $\overline{A_{6}}$ & 0,2 & 0,75 & 0,6 & 1 & 0,25 & 1,46 \\
\hline 7 & $\mathrm{~A}_{7}$ & 0,6 & 1 & 0,6 & 1 & 0,25 & 1,85 \\
\hline 8 & $\mathrm{~A}_{8}$ & 0,8 & 0,75 & 0,6 & 1 & 0,75 & 2,26 \\
\hline 9 & $\mathrm{~A}_{9}$ & 0,4 & 0,75 & 0,6 & 1 & 0,25 & 1,56 \\
\hline 10 & $\mathrm{~A}_{10}$ & 0,8 & 1 & 0,8 & 1 & 0,75 & 2,55 \\
\hline 11 & $\mathrm{~A}_{11}$ & 0,6 & 0,75 & 0,6 & 1 & 0,75 & 2,16 \\
\hline
\end{tabular}

\begin{tabular}{|c|c|c|c|c|c|c|c|}
\hline 12 & $\mathrm{~A}_{12}$ & 0,6 & 0,5 & 0,6 & 1 & 0,25 & 1,48 \\
\hline 13 & $\mathrm{~A}_{13}$ & 0,2 & 1 & 0,8 & 1 & 0,25 & 1,75 \\
\hline 14 & $\mathrm{~A}_{14}$ & 0,2 & 0,5 & 0,4 & 1 & 0,25 & 1,18 \\
\hline 15 & $\mathrm{~A}_{15}$ & 0,2 & 0,75 & 0,6 & 1 & 0,5 & 1,71 \\
\hline 16 & $\mathrm{~A}_{16}$ & 0,2 & 0,5 & 0,4 & 1 & 0,25 & 1,18 \\
\hline 17 & $\mathrm{~A}_{17}$ & 0,2 & 0,75 & 0,6 & 1 & 0,25 & 1,46 \\
\hline 18 & $\mathrm{~A}_{18}$ & 0,4 & 0,75 & 0,6 & 1 & 0,25 & 1,56 \\
\hline 19 & $\mathrm{~A}_{19}$ & 0,4 & 0,75 & 0,4 & 0,75 & 0,25 & 1,40 \\
\hline 20 & $\mathrm{~A}_{20}$ & 1 & 1 & 0,4 & 0,75 & 1 & 2,64 \\
\hline 21 & $\mathrm{~A}_{21}$ & 0,4 & 0,5 & 0,4 & 0,75 & 0,25 & 1,21 \\
\hline 22 & $\mathrm{~A}_{22}$ & 1 & 0,75 & 0,4 & 0,75 & 1 & 2,45 \\
\hline 23 & $\mathrm{~A}_{23}$ & 0,4 & 0,75 & 0,6 & 0,75 & 0,25 & 1,50 \\
\hline 24 & $\mathrm{~A}_{24}$ & 0,8 & 1 & 0,8 & 0,75 & 0,75 & 2,49 \\
\hline 25 & $\mathrm{~A}_{25}$ & 0,4 & 1 & 0,6 & 0,75 & 0,75 & 2,19 \\
\hline 26 & $\mathrm{~A}_{26}$ & 0,6 & 0,5 & 0,6 & 0,75 & 0,25 & 1,41 \\
\hline 27 & $\mathrm{~A}_{27}$ & 0,6 & 0,5 & 0,4 & 0,75 & 0,75 & 1,81 \\
\hline 28 & $\mathrm{~A}_{28}$ & 0,8 & 1 & 0,8 & 0,75 & 0,25 & 1,99 \\
\hline 29 & $\mathrm{~A}_{29}$ & 0,4 & 0,75 & 0,8 & 0,75 & 0,25 & 1,60 \\
\hline 30 & $\mathrm{~A}_{30}$ & 0,8 & 1 & 1 & 0,75 & 0,75 & 2,59 \\
\hline 31 & $\mathrm{~A}_{31}$ & 0,2 & 1 & 1 & 0,75 & 1 & 2,54 \\
\hline 32 & $\mathrm{~A}_{32}$ & 0,4 & 0,5 & 0,4 & 0,75 & 0,25 & 1,21 \\
\hline 33 & $\mathrm{~A}_{33}$ & 0,6 & 1 & 0,8 & 0,75 & 0,25 & 1,89 \\
\hline 34 & $\mathrm{~A}_{34}$ & 0,2 & 0,75 & 0,8 & 0,75 & 0,25 & 1,50 \\
\hline 35 & $\mathrm{~A}_{35}$ & 0,6 & 0,75 & 0,6 & 0,5 & 0,25 & 1,54 \\
\hline 36 & $\mathrm{~A}_{36}$ & 0,8 & 1 & 0,8 & 0,5 & 0,25 & 1,93 \\
\hline 37 & $\mathrm{~A}_{37}$ & 0,4 & 1 & 1 & 0,5 & 0,75 & 2,33 \\
\hline 38 & $\mathrm{~A}_{38}$ & 0,4 & 0,75 & 0,4 & 0,5 & 0,25 & 1,34 \\
\hline 39 & $\mathrm{~A}_{39}$ & 0,4 & 0,75 & 0,6 & 0,5 & 0,25 & 1,44 \\
\hline 40 & $\mathrm{~A}_{40}$ & 0,2 & 1 & 0,8 & 0,5 & 0,25 & 1,63 \\
\hline 41 & $\mathrm{~A}_{41}$ & 0,2 & 1 & 0,6 & 0,5 & 0,25 & 1,53 \\
\hline 42 & $\mathrm{~A}_{42}$ & 0,4 & 0,75 & 0,6 & 0,5 & 0,25 & 1,44 \\
\hline 43 & $\mathrm{~A}_{43}$ & 0,6 & 1 & 1 & 0,5 & 0,75 & 2,43 \\
\hline 44 & $\mathrm{~A}_{44}$ & 0,8 & 1 & 1 & 0,5 & 0,75 & 2,53 \\
\hline 45 & $\mathrm{~A}_{45}$ & 0,8 & 1 & 0,8 & 0,5 & 0,25 & 1,93 \\
\hline 46 & $\mathrm{~A}_{46}$ & 0,4 & 1 & 1 & 0,5 & 0,75 & 2,33 \\
\hline 47 & $\mathrm{~A}_{47}$ & 0,8 & 1 & 0,8 & 0,5 & 0,25 & 1,93 \\
\hline 48 & $\mathrm{~A}_{48}$ & 0,2 & 0,5 & 0,4 & 0,5 & 0,25 & 1,05 \\
\hline 49 & $\mathrm{~A}_{49}$ & 0,6 & 1 & 1 & 0,5 & 0,75 & 2,43 \\
\hline 50 & $\mathrm{~A}_{50}$ & 0,8 & 1 & 0,8 & 0,5 & 0,75 & 2,43 \\
\hline
\end{tabular}


Dari tabel IV.11 sudah jelas bahwa nilai terbesar ada pada V1 sehingga alternatif A1 atau siswa yang bernama Ade Futri adalah alternatif yang terpilih sebagai alternatif terbaik dengan hasil akhir $=2,90$.

Namun pada kasus ini alternatif yang terbaik adalah beberapa siswa yang mendapat nilai pembobotan cukup pada setiap kriteria.

Pengolahan Data dan Perhitungan dengan Software Microsoft Excel 2010 Menggunakan Metode Simple Additive Weghting (SAW)

\section{Hasil Perangkingan}

\begin{tabular}{|c|c|c|c|}
\hline \multirow[b]{2}{*}{ No } & \multirow[b]{2}{*}{ Alternatif } & \multicolumn{2}{|c|}{ Hasil Akhir } \\
\hline & & $\begin{array}{l}\text { Jumlah } \\
\text { Akhir }\end{array}$ & Rangking \\
\hline 1 & $A_{1}$ & 2,90 & 1 \\
\hline 2 & $\mathrm{~A}_{20}$ & 2,64 & 2 \\
\hline 3 & $A_{30}$ & 2,59 & 3 \\
\hline 4 & $\mathbf{A}_{10}$ & 2,55 & 4 \\
\hline 5 & $A_{31}$ & 2,54 & 5 \\
\hline 6 & $\mathrm{~A}_{44}$ & 2,53 & 6 \\
\hline 7 & $\mathbf{A}_{24}$ & 2,49 & 7 \\
\hline 8 & $\mathrm{~A}_{22}$ & 2,45 & 8 \\
\hline 9 & $\mathrm{~A}_{43}$ & 2,43 & 9 \\
\hline 10 & $\mathbf{A}_{49}$ & 2,43 & 10 \\
\hline 11 & $A_{50}$ & 2,43 & 11 \\
\hline 12 & $A_{37}$ & 2,33 & 12 \\
\hline 13 & $\mathrm{~A}_{46}$ & 2,33 & 13 \\
\hline 14 & $A_{8}$ & 2,26 & 14 \\
\hline 15 & $A_{25}$ & 2,19 & 15 \\
\hline 16 & $\mathbf{A}_{11}$ & 2,16 & 16 \\
\hline 17 & $A_{28}$ & 1,99 & 17 \\
\hline 18 & $A_{36}$ & 1,93 & 18 \\
\hline 19 & $\mathrm{~A}_{45}$ & 1,93 & 19 \\
\hline 20 & $\mathrm{~A}_{47}$ & 1,93 & 20 \\
\hline 21 & $A_{33}$ & 1,89 & 21 \\
\hline
\end{tabular}

\begin{tabular}{|l|l|l|l|}
\hline 22 & $\mathbf{A}_{7}$ & 1,85 & 22 \\
\hline 23 & $\mathbf{A}_{27}$ & 1,81 & 23 \\
\hline 24 & $\mathbf{A}_{4}$ & 1,76 & 24 \\
\hline 25 & $\mathbf{A}_{5}$ & 1,75 & 25 \\
\hline 26 & $\mathbf{A}_{13}$ & 1,75 & 26 \\
\hline 27 & $\mathbf{A}_{15}$ & 1,71 & 27 \\
\hline 28 & $\mathbf{A}_{40}$ & 1,63 & 28 \\
\hline 29 & $\mathbf{A}_{29}$ & 1,60 & 29 \\
\hline 30 & $\mathbf{A}_{2}$ & 1,56 & 30 \\
\hline 31 & $\mathbf{A}_{9}$ & 1,56 & 31 \\
\hline 32 & $\mathbf{A}_{18}$ & 1,56 & 32 \\
\hline 33 & $\mathbf{A}_{35}$ & 1,54 & 33 \\
\hline 34 & $\mathbf{A}_{41}$ & 1,53 & 34 \\
\hline 35 & $\mathbf{A}_{23}$ & 1,50 & 35 \\
\hline 36 & $\mathbf{A}_{34}$ & 1,50 & 36 \\
\hline 37 & $\mathbf{A}_{12}$ & 1,48 & 37 \\
\hline 38 & $\mathbf{A}_{6}$ & 1,46 & 38 \\
\hline 39 & $\mathbf{A}_{17}$ & 1,46 & 39 \\
\hline 40 & $\mathbf{A}_{39}$ & 1,44 & 40 \\
\hline 41 & $\mathbf{A}_{42}$ & 1,44 & 41 \\
\hline 42 & $\mathbf{A}_{26}$ & 1,41 & 42 \\
\hline 43 & $\mathbf{A}_{19}$ & 1,40 & 43 \\
\hline 44 & $\mathbf{A}_{38}$ & 1,34 & 44 \\
\hline 45 & $\mathbf{A}_{21}$ & 1,21 & 45 \\
\hline 46 & $\mathbf{A}_{32}$ & 1,21 & 46 \\
\hline 47 & $\mathbf{A}_{3}$ & 1,18 & 47 \\
\hline 48 & $\mathbf{A}_{14}$ & 1,18 & 48 \\
\hline 49 & $\mathbf{A}_{16}$ & 1,18 & 49 \\
\hline 50 & $\mathbf{A}_{48}$ & 1,05 & 50 \\
\hline & & & \\
\hline
\end{tabular}

Gambar IV.4.

Hasil Perangkingan

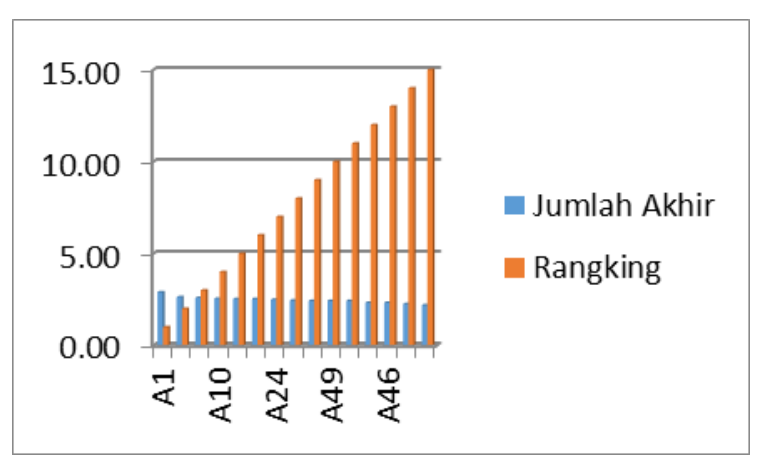

Gambar IV.5.

Diagram Hasil Penelitian

\section{KESIMPULAN}

Setelah melakukan penelitian, pembahasan dan pengkajian tentang sistem pendukung keputusan pemilihan penerima Kartu Indonesia Pintar, dapat diambil beberapa kesimpulan sebagai berikut:

1. Kualitas kegunaan berpengaruh signifikan dan positif terhadap keputusan penerima,

2. Program sistem penunjang keputusan seleksi penerima Bantuan Kartu Indonesia Pintar ini dapat membantu proses pemilihan siswa yang layak menerima Kartu KIP.

3. Terciptanya sistem penunjang keputusan untuk 
menentukan penerima KIP dengan metode Fuzzy SAW.

4. Semakin banyak Sample data yang digunakan maka semakin tinggi pula tingkat validitas perhitungan yang dihasilkan.

\section{REFERENSI}

Eniyati, Sri. 2011. Perancangan Sistem Pendukung Pengambilan Keputusan Untuk Penerima Beasiswa dengan Metode SAW (Simple Additive Weghting). ISSN: 0854-9524. DINAMIK Vol.16 No.2. Juli 2011:171-176

Hamdu, Ghullam. Lisa Agustina 2011. Pengaruh Motivasi Belajar Siswa terhadap Prestasi Belajar IPA di Sekolah Dasar. ISSN: 1412 565X. Tasikmalaya : Jurnal Penelitian Pendidikan, Vol.12 No.1 April 2011: 81-86.

Kusumadewi, Sri. Hari Purnomo. 2013. Aplikasi Logika Fuzzy. Yogyakarta: Graha Ilmu.

Riduwan, 2013. Skala Pengukuran VariabelVariabel Penelitian. Bandung. Alfabeta

Riyanto, Eko. Mahmudi. 2015. Rancangan Bangun Sistem Penentuan Penerima Kartu Perlindungan Sosial (KPS) dengan Metode Simple Additive Weighting (SAW) berbasis Web. ISSN: 1907-2074. Semarang: HimsyahTech Vol.11 No.1, Januari 2015.

Supriyati, Wiwit. 2014. Rancang Bangun Aplikasi Sistem Pendukung Keputusan Penerima Beasiswa dengan Metode SAW. ISSN: 2354577. Surakarta: Citec Journal, Vol.1 No.1 November 2013-Januari 2014: 67-75.

Sugiyono. 2015. Metode Penelitian Manajemen. Bandung. Alfabeta.

\section{PROFIL PENULIS}

Andi Saryoko, M.Kom. Lahir di kota Klaten, Jawa
Tengah pada tanggal 04 Oktober 1981. Tamat program Diploma III (D3) tahun 2005 Program Studi Komputerisasi Akuntansi di AMIK BSI Jakarta, Tamat S1 tahun 2008 Program Studi Sistem Informasi di STMIK Nusa Mandiri Jakarta, Tamat S2 tahun 2011 Program Studi Ilmu Komputer (S2) Konsentrasi Management Information System di Program Pasca Sarjana STMIK Nusamandiri Jakarta. Menjadi Dosen tetap di AMIK BSI Jakarta sejak tahun 2008, dan memiliki Jabatan Fungsional Dosen Asisten Ahli. Kemudian menjadi Dosen Tetap STMIK Nusa mandiri Jakarta sejak tahun 2014 . Sudah pernah melakukan penelitian dan artikelnya pernah terbit di beberapa jurnal, antara lain Jurnal Teknologi, Jurnal Cakrawala, dan Jurnal Pilar, dll.

Sholihin Muttaqin Adalah mahasiswa Sekolah Tinggi Manajemen Informatika Komputer Nusa Mandiri Jakarta Program studi sistem informasi.

Rahmat Hidayat, lahir di Sumedang tanggal 11 Mei 1983. Selama sekolah SD sampai dengan SMU penulis menghabiskan waktu di kampung halaman tercinta yaitu Sumedang. Mengawali karir sebagai asisten laboratorium setelah lulus D3 pada tahun 2009 di kampus BSI Margoda. Melanjutkan kuliah S1 dan lulus pada tahun 2010 dan menjadi Staff BAAK BSI di bagian tim jadwal, dimana tugastugas yang di kerjakan di tim jadwal membuat jadwal dan memploting dosen-dosen yang ada di kampus Bina Sarana Informatika(BSI). Disamping menjadi staff BAAK, penulis juga melaksanakan tridharma sebagai pengajar. Penulis melanjutkan kuliah S2 dan lulus di tahun 2015 dengan bidang ilmu komputer. Untuk saat ini penulis menjadi staff Pusat Penelitian dan Pengabdian (PPPM) BSI dan lulus jabatan fungsional untuk Asisten Ahli tahun 2017. 